\title{
$092 \quad$ MICROVASCULAR OBSTRUCTION AND INTRAMYOCARDIAL HAEMORRHAGE INFLUENCES INFARCT ZONE CONTRACTILE RECOVERY IN REPERFUSED ACUTE MYOCARDIAL INFARCTION
}

A Kidambi, A N Mather, M Motwani, P Swoboda, A Uddin, J P Greenwood, S Plein University of Leeds

doi:10.1136/heartjnl-2013-304019.92

Introduction Following acute myocardial infarction (AMI), microvascular obstruction (MO) and intramyocardial haemorrhage (IMH) adversely affect left ventricular (LV) remodelling and prognosis independently of infarct size. The mechanisms by which $\mathrm{MO}$ and IMH affect LV remodelling are poorly understood. We aimed to investigate how $\mathrm{MO}$ and IMH influence regional contractile function and contractile recovery in patients with reperfused AMI. We measured infarcted and remote myocardial strain at four time points post-AMI, stratified by presence of $\mathrm{MO}$ and IMH.

Methods Thirty-nine patients underwent cardiovascular magnetic resonance (CMR) on a $1.5 \mathrm{~T}$ system with $\mathrm{T} 2$-weighted and $\mathrm{T} 2 *$ imaging, late gadolinium enhancement (LGE) and myocardial tagging at 2, 7, 30 and 90 days following primary percutaneous coronary intervention for AMI. Slice geometry and positioning was identical between sequences. LGE images were used to identify the infarct zone and MO. A hypointense core on both T2-weighted and $\mathrm{T}^{*}$ images was used to define IMH. Circumferential Lagrangian strain was measured at endocardial, mid-myocardial and epicardial layers through the infarct and remote zones.

Results Patient characteristics were similar between those with and without $\mathrm{MO}$ or IMH (table 1). The infarct zone demonstrated recovery of strain with time $(p \leq 0.01$, figure 1$)$. Epicardial strain recovered over time in the presence of $\mathrm{MO}$ with $\mathrm{IMH}$ and without IMH, $(p=0.03, p<0.01$ respectively), but mid-myocardial or endocardial strain did not (mid-myocardium: $p=0.05, p=0.12$; endocardium: $p=0.27, p=0.05$ ). By day 90 , infarcts with $\mathrm{MO}$ had more attenuated strain than those without $(p<0.01)$; those with IMH were attenuated further $(p<0.01)$. Remote myocardial strain was similar across groups at all time points, regardless of infarct

Table 1

\begin{tabular}{lrrrr}
\hline & $\begin{array}{l}\text { No M0 or IMH } \\
(\mathbf{n = 1 7 )}\end{array}$ & $\begin{array}{l}\text { M0 only } \\
(\mathbf{n = 8})\end{array}$ & $\begin{array}{l}\text { M0 and IMH } \\
(\mathbf{n = 1 4 )}\end{array}$ & $\begin{array}{l}\text { p } \\
\text { Value }\end{array}$ \\
\hline Age, years & $58 \pm 10$ & $55 \pm 9$ & $59 \pm 8$ & 0.70 \\
Male & $16(94 \%)$ & $8(100 \%)$ & $10(71 \%)$ & 0.12 \\
Current smoker & $9(53 \%)$ & $4(50 \%)$ & $7(50 \%)$ & 1.00 \\
Hypertension & $7(41 \%)$ & $3(38 \%)$ & $1(7 \%)$ & 0.08 \\
Hypercholesterolaemia & $11(65 \%)$ & $3(38 \%)$ & $8(57 \%)$ & 0.50 \\
Hypercholesterolaemia & $0(0 \%)$ & $1(13 \%)$ & $1(7 \%)$ & 0.31 \\
Pain to balloon time, mins & $205(126)$ & $194(77)$ & $210(200)$ & 0.93 \\
(median (IOR)) & & & & \\
Anterior infarction & $5(29 \%)$ & $4(50 \%)$ & $6(43 \%)$ & 0.53 \\
TIMI flow 3 post PCI & $16(94 \%)$ & $7(88 \%)$ & $14(100 \%)$ & 0.79 \\
\hline
\end{tabular}




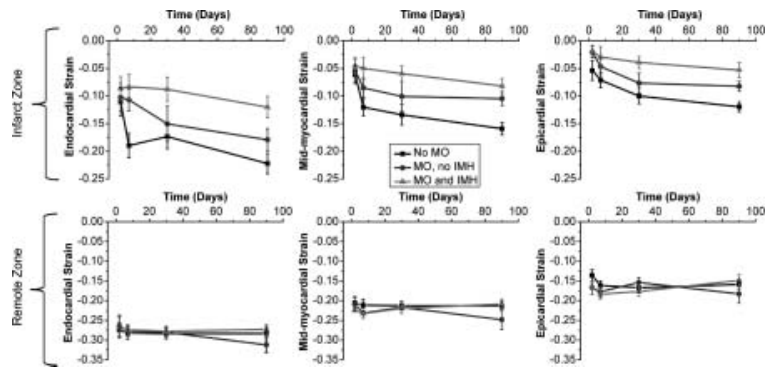

Figure 1

characteristics ( $p>0.2$ for all, figure 1). Infarct transmural extent did not correlate with strain values ( $p>0.05$ at each time point). Multivariable regression showed $\mathrm{MO}$ and IMH to be independently associated with attenuated strain $(p=0.004, p=0.011)$.

Conclusions Contractile function improves within the infarct zone following reperfusion with or without the presence of $\mathrm{MO}$ or IMH. This contractile recovery is diminished in the presence of $\mathrm{MO}$, and further in the presence of IMH. MO and IMH are greater independent predictors of infarct zone contractile recovery than transmural extent of infarction. 